\title{
O uso dos jogos eletrônicos na educação musical e sua possibilidade enquanto recurso didático
}

\section{The use of electronic games in music education and its possibility as a didactic resource}

\author{
DOI: $10.46814 /$ lajdv2n5-017
}

Recebimento dos originais: $10 / 07 / 2020$

Aceitação para publicação: 30/08/2020

\section{Luciana Carolina Fernandes de Faria}

Professora Assistente do curso de Licenciatura em Música da Universidade do Oeste Paulista UNOESTE. Doutora em Tecnologias da Inteligência e Design Digital da Pontifícia Universidade

Católica de São Paulo - PUC/SP. Brasil

E-mail: luciana.carolina@gmail.com

\section{Sheila Regiane Franceschini}

Professora Assistente do curso de Licenciatura em Música da Universidade do Oeste Paulista UNOESTE. Doutoranda em Tecnologias da Inteligência e Design Digital da Pontifícia Universidade

Católica de São Paulo - PUC/SP. Brasil

E-mail: sheilafranceschini@hotmail.com

\section{Karen Rodrigues da Rocha}

Graduanda do curso de Bacharelado em Composição e Regência pelo IA/Unesp. Licenciada em Música pela Universidade do Oeste Paulista - UNOESTE. Especialista em Trilha Sonora:

Composição para Cinema e TV - Universidade Anhembi Morumbi.

Multimedios, Tecnologías e Innovaciones en la educación musical: recursos, abordajes y reflexiones.

Brasil

E-mail: k.rocha@unesp.br

\section{RESUMO}

Diante dos desafios contemporâneos de promover uma educação de qualidade, pesquisadores e professores têm buscado discutir novas estratégias de ensino que envolva os alunos no processo de aprendizagem e que contribuam para uma formação integral e autônoma. Considerando que as novas tecnologias digitais e os jogos eletrônicos atraem jovens e adultos, pesquisadores e leigos, e estão presentes em grande parte da vida cotidiana das pessoas, discute-se a potencialidade de tais meios aplicados à educação e à produção artística. Assim, este artigo tem por objetivo identificar e descrever alguns jogos eletrônicos, educativos ou comerciais, que abordem conteúdo musical, a fim de compreender como estes jogos podem contribuir para a educação musical no contexto escolar. Para isto, foram analisados três jogos com temática musical, dois comerciais para videogame, e um educativo para computador, a fim de descobrir como cada jogo aborda e desenvolve os aspectos musicais em seu contexto. Como resultado, constatou-se que cada jogo, de acordo com seus limites, proporciona uma experiência musical, com estímulo auditivo em relação a elementos musicais como parâmetros do som, frases, articulações, etc. Destacou-se, além disso, que os jogos comerciais abordam os conteúdos musicais de forma lúdica e descompromissada, levando o jogador a vivenciar experiências musicais mesmo sem se dar conta disto, e sem a obrigação de cumpri o jogo como uma tarefa escolar. Todo jogo é por sua essência envolvente e interativo, exigindo do jogador uma atenção perceptiva e sua participação ativa. Assim, conclui-se que o jogo, seja educativo ou de 
entretenimento, pode servir como um recurso pedagógico envolvente, que contribua um aprendizado autônomo e prazeroso.

Palavras-chave: Música e tecnologia, Jogos eletrônicos e música, Educação Musical e videogame.

\begin{abstract}
Facing contemporary challenges of promoting quality education, researchers and teachers have sought to discuss new teaching strategies that involve students in the learning process and contribute to an integral and autonomous education. Considering that new digital technologies and electronic games attract young people and adults, researchers and lay people, and are present in much of people's daily life, the potential of such means applied to education and artistic production is discussed. Thus, this article aims to identify and describe some video games, educational or commercial, that address musical content, in order to understand how these games can contribute to music education in the school context. For this, we analyzed three games with musical theme, two commercials for video games, and one educational for computer, in order to discover how each game approaches and develops the musical aspects in its context. As a result, it was found that each game, according to its limits, provides a musical experience, with auditory stimulus in relation to musical elements such as sound parameters, phrases, articulations, etc. It was also highlighted that commercial games approach musical content in a playful and uncompromising way, leading the player to experience musical experiences even without realising it, and without the obligation to fulfill the game as a school task. Every game is by its engaging and interactive essence, requiring the player a perceptive attention and its active participation. Thus, it is concluded that the game, whether educational or entertainment, can serve as an engaging pedagogical resource, which contributes an autonomous and pleasurable learning.
\end{abstract}

Keywords: Music and technology, Video games and music, Music education and video games.

\title{
1 INTRODUÇÃO
}

A partir de 2008, com a sanção da lei $\mathrm{n}^{\mathrm{o}} 11.769^{1}$, que torna a música conteúdo obrigatório, embora não exclusivo na grade curricular da Educação Básica, surgiu a necessidade de discutir a importância da educação musical na formação humana. Com isso surgiram diversas pesquisas que discutem e tentam esclarecer o significado e a importância da educação musical e também como garantir que ela realmente aconteça, já que o número de professores licenciados é muito baixo.

A educação musical contribui para a formação integral do ser humano e faz com que ele tenha acesso à cultura, patrimônio da humanidade e direito de todo cidadão, além de possibilitar o desenvolvimento da audição e potencializar sua ação no mundo, pois o aluno encontra uma nova maneira de experimentar o mundo quando começa a perceber os sons do ambiente. O mundo é um ambiente sonoro e não podemos ignorar os sons que nos rodeiam.

A paisagem sonora é o nosso ambiente sonoro, o sempre presente conjunto de sons, agradáveis e desagradáveis, fortes e fracos, ouvidos ou ignorados, com os quais vivemos. Do zumbido das

\footnotetext{
${ }^{1}$ Lei de Diretrizes e Bases da Educação, para dispor sobre a obrigatoriedade do ensino da música na educação básica.
} 
abelhas ao ruído da explosão, esse vasto compêndio, sempre em mutação, de cantos de pássaros, britadeiras, música de câmara, gritos, apitos de trem e barulho de chuva tem feito parte da existência humana. (SCHAFER, 2011, contracapa).

O ser humano pode melhorar sua ação no mundo ao desenvolver a percepção auditiva. Com isso, mostra- se uma consciência da ecologia sonora, que é promovida pela educação musical. Isso faz com que o aluno se torne capaz de manipular o som, que é matéria prima da música e se expressar por meio dessa arte.

Enquanto a linguagem musical não for pensada como uma das formas de conhecimento que integra a formação da personalidade humana, o ensino musical será visto como ensinamento acessório não incorporado à totalidade curricular, quando comparado a áreas bem mais estruturadas, o que inviabiliza uma atuação funcional eficiente. (LIMA, 2003, p.84)

Do mesmo modo que a educação física nas escolas não tem o objetivo de formar atletas, a educação musical também não visa à formação profissional de músicos, mas sim de fazer com que a música seja um processo de construção envolvendo a percepção, a criatividade e a reflexão.

Nesse sentido, importa, prioritariamente, a criança, o sujeito da experiência, e não a música, como muitas situações de ensino musical insistem em considerar. A educação musical não deve visar à formação de possíveis músicos do amanhã, mas sim à formação integral das crianças de hoje.(BRITO, 2003, p.46)

Koellreutter também afirma que a educação musical nas escolas de educação básica não tem o mesmo objetivo das escolas técnicas especializadas em formar instrumentistas, mas sim de contribuir para a formação humana.

Aquele tipo de educação musical não orientado para a profissionalização de musicistas, mas
aceitando a educação musical como meio que tem a função de desenvolver a personalidade do
jovem como um todo; de despertar e desenvolver faculdades indispensáveis ao profissional de
qualquer área de atividade, como, por exemplo, as faculdades de percepção, as faculdades de
comunicação, as faculdades de concentração (autodisciplina), de trabalho em equipe, ou seja, a
subordinação dos interesses pessoais aos do grupo, as faculdades de discernimento, análise e
síntese, desembaraço e autoconfiança, a redução do medo e da inibição causados por
preconceitos, o desenvolvimento de criatividade, do senso crítico, do senso de
responsabilidade, da sensibilidade de valores qualitativos e da memória, principalmente, o
desenvolvimento do processo de conscientização do todo, base essencial do raciocínio e da
reflexão. (KOELLREUTTER, 1998, p.39).

Portanto, a música é uma área fundamental para a formação humana. Mas ainda há dificuldades em promover uma educação musical de qualidade devido ao baixo número de professores licenciados. Por ser obrigatório, é preciso contar com a ação dos professores de artes e professores generalistas, para que se desenvolva um conhecimento musical rico e eficiente. 
Objeto de investigação deste artigo, os jogos e atividades lúdicas são usados de forma pedagógica, promovendo a educação musical no ambiente escolar, pois contribui para o desenvolvimento da percepção musical.

Os jogos sempre estiveram presentes na história da humanidade desde os tempos remotos, onde era possível desenvolver habilidades por meio dos desafios propostos: "entre os egípcios, romanos e maias, o lúdico já tinha sua devida importância, onde os mais velhos aplicavam o lúdico entre os mais jovens para transmitir os valores culturais e conhecimento.” (SOUZA, 1996, p. 343).

Sendo assim, ao serem desafiados, os alunos podem superar as suas dificuldades com a aprendizagem de novas habilidades para avançar os níveis propostos no jogo. Além disso, a atividade irá proporcionar um momento de descontração e lazer, fazendo com que isso seja um diferencial para contribuir com a postura ativa do aluno em relação ao seu processo de aprendizagem e proporcionando-o prazer em aprender.

Os jogos eletrônicos, presentes no cotidiano dos jovens contemporâneos, vêm sendo objeto de investigação de diversos pesquisadores. E podem ser utilizados de forma pedagógica, pois contribuem no desenvolvimento da percepção musical e servem de motivação para os alunos que estão cansados do ensino tradicional. A educação efetiva só ocorre mediante o envolvimento e a ação do aluno fazendo com que ele desperte o interesse pela atividade.

Este artigo tem por objetivo identificar e descrever três jogos eletrônicos que tenham conteúdo musical e compreender como estes jogos podem contribuir para a educação musical no contexto escolar.

\section{METODOLOGIA}

Primeiramente houve uma análise dos jogos a fim de conhecer e explorar as possibilidades pedagógicas e exclusivas de cada jogo, tanto educativos quanto comerciais. Em seguida, os jogos eletrônicos foram analisados e suas fases foram catalogadas para que fosse possível identificar dados como os níveis de dificuldade do jogo, os conteúdos musicais abordados, o tipo de interação proporcionada pelo jogo, entre outros. A partir disso, foi possível identificar possibilidades pedagógicas através desses jogos.

\section{RESULTADOS}

Foram identificados dois grupos de jogos eletrônicos dentre os pesquisados, sendo dois deles desenvolvidos para entretenimento e destinados para funcionar em videogames, e um jogo 
desenvolvido para fins educativos e destinado para computador. Desse modo, foram analisados três jogos com propostas diferentes: Let's Tap, Rocksmith e Zorelha.

O primeiro jogo a ser analisado é o Let's Tap, desenvolvido pela Sega e distribuído para o Nintendo Wii. Seu controle é diferente dos demais controles de outros consoles, este faz uso do wii remote que fica sobre uma superfície plana onde o jogador deve bater as mãos nessa superfície para que acione os comandos do jogo.

O Let's Tap tem várias modalidades de mini-jogos, nem todas são de conteúdo musical, apenas a modalidade que iremos analisar, que se chama "Mantén El Ritmo". Nessa modalidade, são visualizadas esferas de diferentes cores que representam as notas musicais. Cada cor corresponde a uma intensidade diferente, ou seja, azul representa fraco, verde representa médio e vermelho representa forte. Há também duas passagens diferentes, denominadas Roll normal e Roll cresc, na qual o jogador deve efetuar batidas em sequências rápidas durante as passagens. Isso estimula a percepção rítmica e a coordenação motora do jogador em executar essas variações de notas em ritmos e tempos diferentes.

O segundo jogo a ser analisado é o Rocksmith, desenvolvido para Playstation, Xbox e PC. Esse jogo conta com uma interface dinâmica, que chama a atenção do aluno que tem idade mais avançada. Rocksmith é semelhante ao Guitar Hero e ao Rock Band, mas a diferença principal é que ao invés de o jogo contar com um joystick alusivo a uma guitarra, ele irá utilizar como controlador um instrumento real, que pode ser uma guitarra ou até mesmo um contrabaixo, que é conectado por um cabo que liga o instrumento ao console. Seu repertório tem a predominância do Rock, com um repertório de bandas consagradas pelo mundo, fazendo assim com que desperte o interesse das crianças e adolescentes que gostam desse gênero musical.

O jogo cria uma potencialidade de aprendizagem especialmente para jogadores que não tem o domínio do instrumento, assim o jogador terá a possibilidade de conhecer as técnicas especificas do instrumento através do jogo, fazendo com que sejam exploradas as alturas, durações, ritmos e articulações. Esses parâmetros são avaliados para que o jogador avance ou não de nível e, consequentemente o grau de dificuldade do jogo.

O terceiro e último jogo analisado consiste em um software chamado Zorelha, desenvolvido para crianças de quatro a seis anos. Seu objetivo consiste em produzir conhecimento por meio da exploração sonoro-musical através do reconhecimento de timbres. Sem a apresentação de notação musical, a meta é fazer com que a criança desenvolva a percepção auditiva apenas pela sonoridade, fazendo com que a criança tenha atenção para as diversas possibilidades de sons. Sua plataforma é simples e bem fácil de entender. De acordo com o som tocado pelo software, a criança seleciona o 
instrumento correto. Seu repertorio é bem infantil e contém músicas de cantigas. Cada música é gravada em quatro sonoridades diferentes, fazendo com que o aluno reconheça cada sonoridade e identifique os respectivos instrumentos. O Zorelha é um software gratuito e desenvolvido para crianças em processo de alfabetização e capaz de produzir diversão e conhecimento.

\section{DISCUSSÃO}

Há tempos que os jogos são utilizados como recurso pedagógico para ensino de diversos conteúdos. Na educação musical não é diferente, eles também estão presentes. Segundo Santaella e Feitoza, (2009), são elementos que fazem com que o jogador se envolva com o jogo, e, também, aprenda para que consiga superar os desafios apresentados.

Esse envolvimento é como evidencia Freire (1996), uma situação importante para a formação autônoma, pois, para que o aluno seja autor de seu próprio processo de formação, ele deve estar envolvido e ser participante ativo. Sem ação do aluno não há aprendizado efetivo, assim como sem a ação do jogador o jogo não é possível. Nos três jogos estudados, o jogador deve ouvir os sons e as músicas propostas pelo jogo para decidir qual ação tomar. Cada jogo apresenta situações diferentes de aprendizagem.

Primeiro analisamos o jogo Lets 'tap. Esse jogo explora muito mais a percepção rítmica, pois é preciso executar os ritmos e ter precisão em acertar as notas. Seu objetivo é treinar a percepção e consequentemente desenvolver sua capacidade auditiva e a coordenação motora. Além de proporcionar diversão e prazer, o jogador também aprende, pois é preciso que o jogador coordene a força e a precisão para obter mais pontos no jogo e avançar de etapa.

Em seguida, analisamos o jogo Rocksmith. Diferente do anterior explora-se muito mais a interface ao usar instrumentos musicais reais como controlador do jogo. Sua proposta também é diferente, pois apresenta possibilidades pedagógicas que estão diretamente ligadas ao aprendizado das técnicas para tocar guitarra. Além disso, o jogo avalia o desempenho do jogador e propõe novos desafios, como ritmos mais elaborados e sequencias de acordes. Assim como o jogo anterior também estimula a percepção rítmica.

Zorelha foi o último jogo analisado, esse foi criado para crianças de quatro a seis anos, que estão em processo de desenvolvimento da percepção auditiva. Fazendo com que as possibilidades pedagógicas de educação musical sejam criadas e facilitadas. Percebe-se que somente o software Zorelha foi criado para fins educativos, o que facilita a aprendizagem do aluno. Porém o Rocksmith, que possui fins comerciais e o objetivo maior é o entretenimento, também promove a aprendizagem, imersão e interatividade, elementos fundamentais para um aprendizado eficaz. E, contudo, é algo 
prazeroso, não aparentando ser uma tarefa ou obrigação, pois, promove o lazer. Isso faz com que o jogo seja para brincar e estudar, de forma que o aluno aproveite isso integralmente.

\section{CONCLUSÃO}

Através de uma oportunidade onde se possa aprender e brincar, conclui-se que é muito importante desenvolver uma educação atenta em promover o desenvolvimento do aluno como autor do seu aprender. Vivenciando, divertindo-se e sendo satisfatório, aprende-se mais. Isso faz com que surja uma nova possibilidade para levarmos o aprender para fora dos portões das escolas, contribuindo para a formação do aluno.

\section{REFERÊNCIAS}

BRASIL. Lei n. ${ }^{\circ}$ 11.769/08. Altera a Lei no 9.394, de 20 de dezembro de 1996, Lei de Diretrizes e Bases da Educação, para dispor sobre a obrigatoriedade do ensino da música na educação básica. Brasília: DOU. Disponível em: <https://presrepublica.jusbrasil.com.br/legislacao/93321/lei-1176908> Acesso em: 20 out. 2020.

BRITO, T. A. de. Música na educação infantil: propostas para a formação integral da criança. São Paulo: Peirópolis, 2003.

FARIA, L.C.F. Da sala de estar a sala de aula: Educação musical por meio de jogos eletrônicos. 2013. 187f. Dissertação (Mestrado em Educação) - Unoeste, Presidente Prudente.

FREIRE, P. Pedagogia da autonomia: saberes necessários à prática educativa. São Paulo: Paz e Terra, 1996.

KOELLREUTTER, H.-J. Educação musical hoje e, quiça, amanhã. In: LIMA, S.A. (Org.). Educadores musicais de São Paulo: encontro e reflexões. São Paulo: Nacional, 1998. p. 39-45.

LIMA, S. R. A. de. A resolução CNE/CEB 04/99 e os cursos técnicos de música na cidade de São Paulo. Porto Alegre: Revista da Abem, n. 8, p. 81-85, mar. 2003

PFÜTZENREUTER, A.C. Tocar/Jogar Rocksmith: as experiências de flow de jovens guitarristas que jogam games de musica. 2013. 200 f. Dissertação (Mestrado em Música) Instituto de Artes, Universidade Federal do Rio Grande do Sul, Porto Alegre.

SANTAELlA, L; FEITOZA, M. (Org.). Mapa do jogo: a diversidade cultural dos games. São Paulo: Cengage Learning, 2009.

SCHAFER, R.M. A afinação do mundo: uma exploração pioneira pela história passada e pelo atual estado do mais negligenciado aspecto do nosso ambiente: a paisagem sonora. São Paulo: Editora Unesp, 2011.

SOUZA, E. R. O lúdico como possibilidade de inclusão no ensino fundamental. Florianópolis: Revista Motrivivência. V. 8, n. 9, 1996. 